THE UNIVERSAL VALUES OF SCIENCE AND CHINA'S NOBEL PRIZE PURSUIT

$$
\text { Cong Cao }
$$

School of Contemporary Chinese Studies

University of Nottingham

Si Yuan Center, Jubilee Campus

Nottingham NG8 1BB

United Kingdom

Email cong.cao@ nottingham.ac.uk 
THE UNIVERSAL VALUES OF SCIENCE AND CHINA'S NOBEL PRIZE PURSUIT

\begin{abstract}
China does not seem to believe the existence of universally acknowledged values in science and to promote the observation of such values that should be applied to every member of the scientific community and at all times. Or, there is a separation between the practice of science in China and the values represented by modern science. In this context, science, including the pursuit of the Nobel Prize, is more a pragmatic means to achieve the end of the political leadership - the national pride in this case - than an institution laden with values that govern its practices. However, it is the recognition and respect of the latter that could lead to achievement of the former, rather than the other way around.
\end{abstract}

Keywords science; values; Nobel Prize; China 


\section{THE UNIVERSAL VALUES OF SCIENCE AND CHINA'S NOBEL PRIZE PURSUIT}

\section{Introduction}

The Chinese society has been obsessed with and even anxious about winning a Nobel Prize in science. A significant part of its members - from its political and scientific leadership to working scientists to ordinary citizens - is eager for such an internationally well-known prize to symbolically vindicate its status as a rising scientific power and to acquire national prestige (Cao 2004b). The October week when the Nobel Prizes are announced always generates an indescribable unease in China. Knowing that the chance for their scientists to win a Nobel Prize in science is slim, Chinese still hope for a surprise. In 2008, the Nobel Prize in Chemistry went to Roger Y. Tsien, a Chinese-American who happens to be the nephew of Qian Xuesen, known as Hsueh-sen Tsien in the West, father of China's missile and space program; and in 2009 the Nobel Prize in Physics was awarded to Charles K. Kao, a British and American dual citizen of Chinese origin and a resident of Hong Kong - both prizes were celebrated in China as two laureates are somehow related to China and the Chinese people! In 2011, Mo Yan, a mainland Chinese writer, received the Nobel Prize in Literature, putting further pressure on Chinese scientists, who in recent decades were provided with enormous resources for their research and have worked in more liberal environments than writers but have not obtained significant discoveries that could lead to a Nobel Prize. ${ }^{1}$ What has puzzled the Chinese scientific and political leadership most is how the former Soviet Union, on which China modeled to develop its political system and scientific enterprise, could have turned out quite a number of Nobel Prizes in science, especially in physics.

There is no doubt that a wide range of problems and challenges are associated with China's failure to win this internationally prestigious award. They include but are not limited to political interference in the scientific community, lack of leadership talent at the international frontiers of research, lack of tradition of knowledge accumulation, discouragement of challenging the status quo in science as well as other aspects, and deeply rooted problems in its education system. Some of the problems can be fixed sooner while those culturally embedded tend to persist. But at a more fundamental level, as the paper is going to argue, Chinese's growing impatience and frustration with the Nobel Prize - being enthusiastic about it but having failed to get one - seems to boil down to whether and how to

\footnotetext{
${ }^{1}$ In general, the Nobel Prize in science is less biased, compared to its counterparts in peace and literature (for a discussion on the application of the Nobel Prize in Literature to the Chinese case, see Lovell 2006).
} 
embrace the values attached to the prize. In rewarding those who confer the "greatest benefit on mankind," the Nobel Prize in science also represents an appreciation and celebration of not merely breakthroughs, discoveries, and creativity but a universal set of values that are shared and practiced by scientists regardless of nationality and culture. It is the recognition of the latter that could lead to the achievement of the former, rather than the other way around.

Unfortunately, China does not seem to believe the existence of universally acknowledged values of science and fails to vigorously promote the observation of such values that also should be applied to every member of the scientific community and at all times. Or, there is a separation between the practice of science in China and the values represented by the Nobel Prize and modern science. In this context, science, including the pursuit of the Nobel Prize, is more a pragmatic means to achieve the end of the political leadership - the nation's pride in this case.

In this paper, we are going to examine the values of science and especially their acceptance in China, discuss areas of the practices in Chinese science that deviate from such values, and speculate on the root causes why China does not have an environment suitable for breakthroughs that may one day lead to a Nobel Prize. The paper will conclude that a renaissance of the scientific values is the necessary condition for China to become a real scientific power, regardless of its scientists receiving a Nobel Prize.

\section{The Values of Science}

Discussion of the values of science dates back to discussion of ethos or norms of science by the American sociologist Robert K. Merton. In "A Note on Science and Democracy," an essay written in 1942 (or in an earlier essay, "Science and the Social Order," written in 1938) at a time of the contemporary economic crisis, the rise of Nazism and fascism, and the emerging radical and Marxist political activism of scientists in the United States and the United Kingdom (Mendelsohn 1989; Turner 2007), Merton proposed a number of "prescriptions, proscriptions, preferences and permissions" for the members of the scientific community to feel obliged to follow, or "affectively toned complex of values and norms which is held to be binding on scientists" (Merton 1973 [1942]: 268-269; italics added). They include four moral norms or "institutional imperatives" - communism in the sense of communalism, universalism, disinterestedness, and organized skepticism. According to Merton, scientists should selflessly and as widely and quickly as possible share their discovery with the scientific community, whose members should in turn rigorously scrutinize the claim by universalistic, meritocratic and impersonal criteria without taking into account 
race, class, gender, religion, culture, and nationality of the discoverers in the process, and end up with either rewarding them or rejecting the discovery's validity; scientific results should be free from personal or corporate interests and dishonesty and also must be able to withstand systematic doubt. Fifteen years later, Merton added one more item - originality - into his system of scientific norms, suggesting that scientific research should contribute new knowledge (1973 [1957]). Together his normative structure of science has been given the acronym of CUDOS - communalism, universalism disinterestedness, originality, and skepticism.

Empirical study of these norms did not start until the 1960s when Merton and his collaborators investigated how the social system of science operates in accordance with, and also often in contradiction to, the norms of science (Zuckerman 1988: 514-526). But the Mertonian norms have been challenged on a number of fronts (Mulkay 1969; Bourdieu 1975; Collins 1982; Ben-David 1984; Yearley 2005). For example, the set of norms has been criticized for its idealism as "being detached from interests, universal and owned in common by the human race" (Jasanoff 2005: 228), for its ignorance of "the technical substance of science" (Latour and Woolgar 1986: 24), and for falling "short of our objective of understanding both science and the scientists who make it" (Latour and Woolgar 1986: 190). Indeed, in reality, while stimulating important and dynamic science, skepticism can lead to greater secrecy for the sake of personal gains or restriction by the industrial and military competition, which also makes communalism difficult, if not impossible. The norm of universalism has been found to be tainted by commitments to certain people or patterns of thought, making evaluation of scientific work often, if not always, biased. In the meantime, scientists who try too hard to be disinterested might prevent uncertain new areas from being explored and might extinguish the passion that scientific research should inspire. Even pure academic scientists do not necessarily exercise these norms, as they are under constant and mounted pressures to publish papers, to secure funding for their research, and to get promotion, let alone scientists working in industries. In other words, "in practice scientists deviate from at least some of these putative norms with a frequency which is remarkable if we presume that the latter are firmly institutionalized" (Mulkay 1976: 639). In fact, Merton himself acknowledged that the social system of science sometimes did not operate under ideal conditions. For example, the existence of the Matthew Effect violates the norm of universalism; the reward system in science does not always give credit where credit is due famous scientists often receive disproportionate credit for their contributions, whereas credit 
that goes to their lesser known and junior colleagues is less than what their contributions actually merit (Merton 1973 [1968]; Holton 2004).

Alternative accounts also have been proposed. Mitroff (1974), through his story of the Apollo moon scientists, provided empirical evidence to the operation of a set of counternorms - solitariness, particularism, interestedness, and organized dogmatism - in science. Most importantly, the physicist-turned-humanist John Ziman suggested a set of counternorms that could be summarized by the acronym of PLACE - proprietary, local, authority, commissioned, and expert. According to Ziman, modern science produces proprietary knowledge that is not necessarily made public and focused on solving local technical problems; as such, the activity of scientists is controlled by authority and scientists are employed to achieve practical goals as experts. In its most benign form, the prospect of corporate funding may lure scientists away from high risk, novel areas of research toward more readily marketable applications. Thus, it may have more subtle effects on the integrity of the research system (Ziman 1990, 2000). Other scholars also describe the shift of knowledge production from investigators-initiated and disciplinary-based "Mode 1" academic science to "Mode 2," where the rise of application-focused and interdisciplinary science commands a different set of norms and values (Gibbons et al. 1994).

Nonetheless, these debates do not mean to deny the necessity of certain norms or values - CUDOS, PLACE or others - to govern the behavior and practice of scientists. According to Kalleberg, "there is an ethos of science influencing scientific conduct ... the performance of contradictions of several critics actually confirm the existence of such an ethos" (2007a: 133); therefore, the concept of the norms of science not only was "historically important," but also is "essential today" (2007b: 138). In other words, we should neither deny the existence of the norms of science because of their limited explaining power nor use the existence of violations of such norms or counter-norms as an excuse to reject the necessity to observe these norms. Indeed, there are variations between disciplines, evidential requirements, forms of theory-building, ethics, culture and tradition, varied influences of the scienceindustry interactions, institutional priorities and systems of research assessment, and such variations could be country specific, but the operation of such values or norms is implied in the various sets of guidelines for responsible research practice (IAP-IAC Committee on Research Integrity 2012). Recent empirical studies also have indicated the utility of norms in gauging the behaviors of scientists (Shorett, Rabinow, and Billings 2003; Anderson et al. 2010; Panofsky 2010). 
Furthermore, the norms of science were introduced in a broader context. Merton referred science systematically to "a variety of distinct though interrelated items," ranging from "a set of characteristic methods by means of which knowledge is certified," "a stock of accumulated knowledge stemming from the application of these methods," to "a set of cultural values and mores governing the activities termed scientific;" or any combination of the above three (1973 [1942]: 268). At the operational level, there is scientific methodology; at the materialistic level, science, with activities based on scientific methodology, means research that leads to discoveries and inventions; and culturally, the norms govern the practice of scientists. In this way, science climbs up a hierarchical "value" chain from methodology to materialism and ultimately reaches the height of culture. There is probably something missing in this formulation. Science, as a system, also includes education, research establishments, funding, peer review, communications, and professionalism where culture or values find their location. Finally, science does not operate in a vacuum but interacts with society; therefore, public understanding of science, societal support for science, and impacts of science on society are equally important.

When the Mertonian norms of science were debated and critiqued, however, the attention has not been paid to science as a system. Again, in Kalleberg's view, Merton's norms contain both "technical or cognitive" and "moral or social" aspects (2007b: 140). To better understand modern science, we should take a holistic approach, not merely emphasizing its methodology and materialism; of more significance are both the institution in which science operates and the normative structure that governs its operation. Indeed, it is easier to get the methodological and materialistic perspectives of science right while ignoring other and often more important dimensions. It is against such a backdrop that we start to examine the observation of, or lack thereof, norms or values of science in China.

\section{What Is Valued in Chinese Science?}

Because of its materialistic benefits, science always occupied a privileged position in modern China. While significant technological progress in ancient China has been well documented (Needham Various years), the Chinese embrace of science only dates back to the May 4th Movement in 1919 when "Mr. Science," along with "Mr. Democracy," was introduced (Wang 2011). But not only did the concepts of science and democracy substantially differ from those advocated in the West, they were utilized to attack traditionalism in general and Confucianism in particular. In this context, the introduction of science in the May 4th period was no different from the adoption of the " $t i-y o n g$ " dichotomy 
by the late 19th century reformers, or the predecessors of the May 4th generation, to undermine the feudal court of the Qing Dynasty: "Chinese learning is for fundamental principles ( $t i$ ) while Western learning for practical applications (yong)" (zhong xue wei ti, xi xue wei yong) with techniques merely serving the purpose of preserving the essence of the Chinese culture (Shen and Williams 2005). In other words, the science that was appreciated during the May 4th period was not its Enlightenment values but its pragmatism or utility, or the achievement of modernization without modernity, which unfortunately delayed China's modernization endeavor (Baum 1982).

As this approach deeply rooted in the Chinese culture values utility and practicality, those who had been trained and possessed knowledge in the natural sciences and engineering were offered important positions in areas of their expertise during the Nationalist period (Kirby 1989). In most of the history of the People's Republic, science and technology were considered as integral and overwhelming part of nation-building, whereby members of the technical community contributed their knowledge to achieving the modernization of industry, agriculture, and national defense. There seemed to be a perfect alliance between the $t i$ of communist ideology and the yong of modern science, although from time to time the yong had been perceived anti-ti, as in the Anti-Rightist Movement in 1957, a political campaign against those with the yong or expertise who were considered to try to undermine the $t i$ they served (Schneider 2003). During the Cultural Revolution, intellectuals, including scientists came under unprecedented attack (Wei and Brock 2012).

The appreciation of science as a utility was reinforced in China's reform and opendoor period (Miller 1996). According to Deng Xiaoping, then China's paramount leader, science and technology constitute the primary productive forces, thus giving rise to a series of policy initiatives emphasizing the materialistic aspect of the science and in turn the technocratic domination in the nation's affairs. Since the 1990s, scientists have also been showered with economic incentives, academic "reputation," political access, and in some occasions, even leading government positions, in return for their advice and support of the regime (Pei 2006: 88-95). Indeed, Chinese intellectuals have become pragmatic, willingly trading their independence and autonomy for materialistic affluence.

There are exceptions. The late astrophysicist Fang Lizhi, for example, stood to use the attention given to the yong of science to challenge the $t i$ represented by Marxism and the Communist Party leadership. He asserted that since intellectuals represent the most primary productive forces in society, as Deng indicated, Chinese intellectuals should be the nation's new leading class, not just a social stratum. Fang further argued that the role of intellectuals 
should not be limited to solving technical problems but be extended to providing progress for the entire society (Williams 1990; Miller 1996). While this turned out to be an aborted endeavor, unfortunately, Fang, the challenger to the $t i-y o n g$ division, did not necessarily treat science as an institution and as a value system as well.

The issue underlying the utility of science is much deeper and philosophical in nature, dating back to Francis Bacon's maxim, "knowledge is power." In China, the advocacy of "saving the nation through science" in the Nationalist era (Wang 2002), recent policies such as "revitalizing the nation with science, technology, and education" (kejiao xingguo) and "strengthening the nation through talent" (rencai qiangguo), and the "scientific development outlook" (kexue fazhan guan) have all adhered to this maxim. Reflecting the materialistic emphasis, science is just a means to the political end of making China powerful and prosperous, rather than a "science for Enlightenment" where the importance of science as an institution and a value system is cherished. While this highly utilitarian view of science and technology is rarely questioned, it has become clear that considerable concerns have arisen as to whether the values of science should be a source of as well as a basis for China's renaissance both in science and as a nation (Suttmeier 2011).

\section{The Chinese Approach to Science}

Science continues to gain currency in Chinese society. Reform of the science and technology system, initiated in 1985 and reinforced by a recent national conference on science, technology and innovation as well as a recent document by the Chinese Communist Party (CCP) Central Committee and the State Council, tries to make scientists better serve the economy. The Medium to Long-Term Plan for the Development of Science and Technology (2006-2020) (MLP), released in early 2006, set out goals for China to become an innovationoriented nation by the end of the plan period. China has become the world's factory, turning out many gadgets with increasing technological sophistication. Chinese scientists have begun to publish more papers and file more patent applications, with a small number of elites pursuing the highest level of science that may one day lead to a Nobel Prize. In a word, science and innovation have become China's new "religion." While these are all necessary, the question, then, becomes: Are methodological and materialistic conditions, pursuits, and achievements sufficient for Chinese scientists to better perform their profession? Could China's science and technology attain excellence measured by winning the Nobel Prize by ignoring the universal values of science? 
Here, we would like to examine the types of cross-cutting issues that more explicitly reflect the actual practice of values or norms in Chinese science. We want to use the Chinese approach to reward system, misconduct in science, freedom of inquiry, and most importantly, the autonomy of the scientific community to exemplify whether and how China's pursuit of science may be at the expense of institutional mandate and normative requirement of science, which may in turn hurt China's chance of becoming a truly scientific superpower.

\section{Reward System}

Like other institutions, science has developed an elaborate system for allocating rewards - from publications, citations, grants, promotions, membership in honorific societies, to awards such as the Nobel Prize - to those who achieve the originality and novelty in knowledge production. While stimulating scientific progress, the reward system incentives scientists to pursue excellent at the research frontier.

Nowadays, Chinese institutions of learning put a premium on publishing in international journals catalogued by the Science Citation Index and stipulate rewards accordingly. Unfortunately, the number of papers and where the papers were published are more important than the peer review process. Outsourcing the peer-judged and meritocratic reward system internationally may not be in China's best interests, but this does reflect a lack of confidence within the scientific community in carrying out a fair and impartial assessment. Doing so would not necessarily prevent non-academic factors from getting involved. In practice, regulations could be ignored or interpreted arbitrarily. For example, seniority from time to time overrides achievements; it is not rare that promotion committee members are bribed; personal relations (guanxi), affection (renqing) or face (mianzi) are important considerations; and scientist-turned-administrators are rewarded more favorably.

Such deviance from the values and practices of science has its historical root in China, albeit in very different ways. Awards could be used to serve purpose other than rewarding scientists for their achievements. For example, one of the first-class prizes of the 1956 Natural Science Award, China's first, went to the aeronautics scientist Qian Xuesen who later led China's missile and space program. According to the initial prize rules, the award would not consider work achieved abroad. But a special case was made to include Qian, who returned from the United States in 1955, as an awardee for his 1954 book, Engineering Cybernetics. Measured solely on quality, Qian's work deserved the award, but the decision went beyond the award itself: the government wanted to use it as a gesture to attract more returnees (Li 1995). 
The award system, when restored after the Cultural Revolution, became more materialistic. At one time, award was intended to increase awardees' income and to improve their quality of life as the award not only carried monetary value, albeit nominal, but more importantly would entitle awardees other material benefits such as promotion, bonus, and housing from the work unit (danwei) where the awardees worked. Until recently, there were awards from the national, provincial, and ministerial down to the individual danwei levels. More problematic is that awards are not nominated by peers, a common practice for any award, including the Nobel Prize, but applied by scientists themselves. Not only is peer review insufficiently rigorous, the awards process also involves various behind-the-scene activities. Scientist-turned-administrators overwhelm the list of awardees, taking excessive credit from the scientists at the front line. For example, eight of the eleven first-class awards of the National Science and Technology Progress Award in 2009 went to administrators, including vice minister, university presidents, bureau chiefs, chief executives and others (Bi 2009). Worse, supporting materials for awards often are exaggerated or even deceptive. For example, in 2007, a National Science and Technology Progress Award was given to Sanlu Group, a milk powder producer, for its innovative baby formula, which turned out to be a scandal of the addition of melamine (Ye 2009). In early 2011, China's Ministry of Science and Technology (MOST) had to revoke a National Science and Technology Progress Award to Xi' an Jiaotong University in 2005 for the plagiarism and falsification of the economic payoffs of the research associated with the award (Ye and Lei 2011).

Among the grievances toward China's reward system is that toward members (academicians, yuanshi) of the Chinese Academy of Sciences (CAS) and of the Chinese Academy of Engineering (CAE). The elite membership means more than the highest academic honor that the nation bestows on its scientists and engineers (Cao 2004a). For one thing, Chinese yuanshi are entitled to not only a small stipend from the state but also lifetime employment, and de facto privileges equivalent to a vice governor in housing, medical care, and travel, as well as other benefits from regional governments and their danwei. $^{2}$ Membership also means a high likelihood that its holders serve on expert panels and lead national research programs, putting themselves in advantageous positions to secure research funding and support for themselves, their students, colleagues, collaborators, and danwei. As

\footnotetext{
${ }^{2}$ In 1993, the Chinese state stipulated giving yuanshi a monthly stipend of RMB200, which was substantial back then. Now, the stipend has been raised to RMB1,000 (US\$160) a month. The yuanshi are not supposed to receive any other benefits. Holing a lifetime elite membership, Chinese yuanshi enjoy the benefit of lifetime employment.
} 
a result, there has been a mania toward yuanshi. Some provinces and danwei use higher salaries, lucrative start-up packages, relocation help, and housing to lure yuanshi and even make concurrent appointments to raise their interests, hoping that associations with these names bring in fame and gain. Some candidates for the membership launch public relation campaigns to promote themselves, turning the election that is supposed to involve existing yuanshi only into one in which candidates play active roles. With the huge benefits inherent in the yuanshi title, it is also not rare that institutions of learning promote their candidates. Worse, cliques have formed among some yuanshi who effectively block others from entering the elite rank, as was the case in the 2011 CAS membership election.

While the elitism, which is still new to China, reflects the strengthening of values such as meritocracy and academic autonomy, some yuanshi utilize their status to engage in activities that compromise these values. A considerable number of them, due to their arrogant, overweening, and supercilious behavior, are called "academic hegemons" (xueba).

Colleagues have to surrender first or corresponding authorship to them even they do not contribute to the work. Because of the unintended consequences, the elite membership has seen the reputation damaged, which also explains why there have been calls to overhaul, if not abolish, the yuanshi institution.

\section{Attitude toward Scientific Misconduct}

Closely related to the problematic reward system is the widespread of scientific misconduct or fraud in China. In early 2010, The Lancet and Nature, two leading international science journals, published editorial and news respectively, condemning a case in which scientists at China's Jinggangshan University withdrew some 70 papers submitted to Acta Crystallographica Section E for fabrication and urging strongly that China take action to clean house (The Lancet 2010; Qiu 2010). The case indicates that misconduct must have been more serious than any observer of Chinese science could imagine as such an unknown thirdtier institution as Jinggangshan University in inland China has got the international scrutiny. More broadly, a study of retraction of papers published in journals catalogued by ScienceDirect, one of the world's leading databases of scientific, technical, and medical literature, indicates that Chinese authors had withdrawn the most papers between 2008 and 2010 and their pattern in plagiarism and duplication of publications was no different from that of scientists in other countries (Liu and Hu 2011). Submission to domestic journals is worse with plagiarism alone accounting for $31 \%$ of the papers submitted to a journal run by a leading university (Zhang 2010). In fact, according to a survey of Chinese scientific 
professionals by the China Association for Science and Technology, 55.5 percent of them were definitely aware of academic misconduct committed by their fellow researchers, including infringement upon others' research achievements, plagiarism, fraud, and duplications in submission (CAST 2009). Even conservative estimates indicate that around one-third of Chinese researchers have engaged in practices that violate standards of research conduct such as falsification of data and plagiarism (Qiu 2010).

Burned in these statistics are some notorious cases. One such case that is particularly worth mentioning is the horrendous "Hanxin" digital signal processing chip scandal that shocked the Chinese as well as the international scientific community (Barboza 2006). In early 2006, Chen Jin, a computer scientist at Shanghai Jiaotong University and a returnee from the United States, was found to have fooled his university, experts who had appraised his "achievements," and government agencies that had allocated hundreds of millions to his research for more than three years by using the fake chips. In fact, the so-called "Hanxin" chips, which Chen claimed to have broken the foreign dominance so as to become a star scientist and even a national hero, were simply bought from Motorola with the original logo scratched off and replaced with his owns. When someone from his group blew the whistle on the Internet, which then proved to be true, Chen was merely deprived of all the honors showered on him and positions at the university and elsewhere. He was not investigated for cheating and possible criminal activities. By contrast, a fellow Korean cheater Hwang Woosuk was given a two-year suspended prison sentence by the Seoul Central District Court after being found guilty of embezzlement and ethical violations short of fraud. Nor have there been investigations into the role played by the appraisers of Chen's "achievements," the wrongdoing by organizations that had given him numerous awards, and the negligence of government agencies that used public expenditure to support to Chen and his projects.

Sociologically, the fraudulent behavior of scientists is attributed to individual's disordered emotions and mentality, conflicts between ethical standards of conduct and a desire to attain status, and alienation from the social organization for ambivalent behavior (Zuckerman 1988: 520-526). On top of these, the rising scientific misconduct in China resulted from the pursuit of promotions and other material rewards, and a hypercompetitive environment for funding. Moreover, the competing norms of the Nationalist regime, of the $\mathrm{CCP}$, of the scientific community, and of work unit (danwei), the introduction of international values of science in the reform and open era only has made the situation more complicated (Suttmeier 1985). Chinese scientists have been confused and frustrated as to what norms or values they are expected to observe. 
For example, with an emphasis of publications in SCI journals, or international publications, Chinese institutions of learning have placed more emphasis on quantity, and assessed, promoted, and rewarded their scientists accordingly. When a scientist has difficulty fulfilling the required quantity legitimately, he or she is likely to divide the research into "the least publishable unit," or even take a detour. The societal expectations for Chinese scientists have been on the rise as well. Having in recent years increased its investment in research and development very substantially, the government inevitably has hoped for "visible" outcomes - for example, a Nobel Prize in science in twenty years (Cao 2004b) - coming from some of the leading scientists, which may have further fueled the growing misconduct.

While some of the fraudulent scientists have been caught just because they were "unlucky," arguably many worse cases may have not been revealed (Barboza 2006). More problematically, the institutional watchdog responsible for exposing, investigating, and punishing deviance cases exits on paper only. Since 2005, the National Natural Science Foundation of China has disclosed misconduct cases, including unattributed quotes, plagiarism, falsifying signatures on grant proposals, fabricating credentials and scientific data, and violating application procedures to gain access to funding. Conspicuously, the MOST that distributes more significant public research funds has never disclosed any such case, let alone punished scientists for misconduct. This practice of creating a government agency under $\mathrm{CCP}$ control to discipline scientists while denying their autonomy to self-discipline, plus the lack of vigorous peer review and an open press, as in the West, represents a failure of governance in Chinese science.

Meanwhile, it is extremely difficult to sanction high-profile scientists, because of the interference from both the scientists who have committed the fraud and the political leadership who has made them eminent in the first place. For example, the failure to denounce the involvement of Chen Zhangliang, then vice president of Peking University, one of China's most prestigious universities, in a plagiarism case in the mid-1990s set a very terrible example and opened the floodgates for large numbers of other scientific fraud cases involving high-profile scientists ( $\mathrm{Li}$ and Xiong 1996). ${ }^{3}$ In the most recent case, He Haibo, a junior scientist at Zhejiang University, and Li Lianda, He's advisor, a CAE member at the Chinese Academy of Traditional Medicine who was also concurrently dean of pharmacology at Zhejiang University, were implicated for plagiarism in several withdrawn papers that they

\footnotetext{
${ }^{3}$ Chen later was appointed president of China Agricultural University and now is the vice governor of Guangxi Zhuang Autonomous Region.
} 
co-authored. At the end, He was dismissed, but Li only did not get his deanship reappointed (Cyranoski 2012). Such cases of selective punishment and not punishing senior scientists could have serious consequences in China and beyond as Chinese scientists have increasingly begun to collaborate with foreign counterparts (Zeng and Resnik 2010). ${ }^{4}$

\section{Freedom of Inquiry}

Freedom of inquiry is at the core of modern science and the key to "make for" greatness in science. Though contested, freedom of inquiry is essential to the mission of science. It provides scientists the independence to choose what to study and decide how to do their research without the intrusion of politics or other factors; it encourages them to be skeptical about any discoveries or ideas; it also grants them the right to engage in activities or communicate any ideas or facts, including those controversial, dissident, and inconvenient to political authorities, without fear of repression, sanction, job loss, or imprisonment. Because of the imperatives, leadership at institutions of learning cherishes the value of free inquiry and fiercely fights against any activity that could undermine it (Cole 2010: 63-64 and 114).

Freedom of inquiry is not a new concept to Chinese academics. As early as the 1920s, the renowned historian Chen Yinke, known as Chen Yinque in the West, insisted on the "thoughts of freedom and spirits of independence" in research. Cai Yuanpei, as the president of Peking University between 1916 and 1927, campaigned and practiced the philosophy of freedom of thought and inclusiveness of different schools of thought. China's post-1949 constitution ostensibly guarantees freedom of speech, among many other rights, to its citizens, although in reality Chinese people do not necessarily enjoy such rights or are only allowed to exercise such rights conditionally. There have been too many cases of strict and stern control in social science research and various kinds of policy-related work in the name of stability and harmony. Academics pursuing research in an unorthodox way or critical of the regime are likely to become marginalized if not punished or dismissed. Papers or books that deal with politically incorrect topics are likely to be banned or are published with sensitive parts censored. Ironically, a majority of academics have to exercise self-censorship owing to fear of the authoritarian state.

\footnotetext{
${ }^{4}$ There were several known cases of scientific misconduct involving elite scientists. In 2007, Fan Weicheng, a CAE member at the University of Science and Technology of China, was found plagiarism in three co-authored papers (Liu 2007); and in 2009, Liu Xingtu, also a CAE member, improperly used his colleagues' work (Peng 2009). But their punishment was no more than reprimand or censure.
} 
In general, the natural sciences fare better. Of course, a variation of the Lysenko biology dominated in the early 1950s, resulting in the denunciation and criticism of the Pauling's resonance theory, Morgan's genetics, and Einstein's relativities as pseudo science during different periods of time (Schneider 2003; Hu 2005). The subsequent Cultural Revolution completely destroyed China's higher education and research system. While things have improved in the reform and open-door era, the problem is more generalized absence of a free and open, liberalized intellectual environment in China.

There is still top-down, bureaucratic, and sometimes political interference through science planning. Indeed, the organization of the strategic weapons programs in the $1950 \mathrm{~s}$ and 1960s under the planned economy has left a legacy for China's science and technology. The 15-year MLP represents the most recent effort in this regard. The planning mentality is reflected in setting up research priorities, mobilizing resources, and giving preference to big science at the expense of individual-investigator-based endeavors. At the operational level, bureaucrats rather than scientists channel research funding, often on the basis of guanxi rather than peer review, to mediocre scientists and to projects that might have political visibility. The political leadership also utilizes its influence to promote certain lines of research or directly allocate funds under its discretion to certain projects, as in the cases of hybrid rice and biochips, which received the funding from the Premier's Fund directly and even several times (Poo 2004; Rao, Lu and Tsou 2004).

Genuine academic discussions and debates are rare. In 2004, amid the MLP drafting, both Chinese scientists inside and outside China criticized the national R\&D programs biased and inefficient, lacking in transparency, too often subject to the preferences of government officials rather than scientists, and operated as in the planned economy. As the pursuit of mega-programs that the MLP envisaged might divert resources from programs supporting bottom-up, investigator-driven projects which often produce more original research, they argued for changing the ways of organizing and funding such programs (Cyranoski 2004; Poo 2004; Rao, Lu, and Tsou 2004). But the particular issue of "China Voice II," a Chinese language supplement to Nature, the leading international journal of science, which carried the criticism, was not allowed to be distributed in China with the excuse that a map of China in the issue did not include Taiwan (Nature 2005). In 2005, a proposal to hold a symposium on the reform of China's science and technology system to commemorate the twentieth anniversary of the reform was also suppressed. All this has postponed the reform of the problematic system for seven years until recently when its proper function is in jeopardy. Finally, in early 2012, Science and Culture Review, a bimonthly CAS publication, had to 
destroy copies of its February issue and reprinted it as the leading article in the original one pointed out that the elite yuanshi institution is facing "a crisis of trust," an unfortunate truth.

\section{Autonomy of the Scientific Community}

While it is true that science does not operate in a completely autonomous social and political milieu, the extent to which the problems confronting science in China, discussed above, is attributable to the lack of a genuinely autonomous scientific community in China or the lack of sense of a scientific community (Suttmeier 1987). For one, although China in the reform and open-door era has witnessed the decline of the overwhelming role of danwei in the provision of social services and benefits, this does not fundamentally change the relationship of employees to danwei, which still has leverage to reward or punish its employees, including scientists. Given that, an ordinary scientist may be unwilling, or at least reluctant, to involve too much in activities outside danwei, including those organized by an academic society that is composed of more peers than colleagues in the same danwei. The academic society also may not provide the kind of services and support that its members need or look for. These in turn and inevitably prevent the scientific community from playing a more active role in China. ${ }^{5}$

China's natural scientists have a strong tradition of voluntary, autonomous associations, dating back to the 1914 founding of the Science Society of China by a group of Chinese students in the natural science programs at Cornell University. An emulator of the American Association for the Advancement of Science (AAAS) in the U.S., it became part of the All-China Federation of Natural Science Societies in 1949, when scientists were mobilized to participate in the founding of the People's Republic. The latter organization in turn was the basis for the China Association of Science and Technology (CAST) established in 1958 (Wang, Shen, and Gao 1994: 16-29). During their evolution, however, Chinese professional societies gradually lost their independence.

Nowadays, an academic society, like any non-government organizations in China, has to find a sponsor, usually a government agency or institution, in order to register legally. The academic society also depends upon such an affiliation for funding as philanthropic interests in educational, cultural, and scientific causes are only just emerging. Moreover, the academic society is likely led by a professional-turned-bureaucrat or a retired bureaucrat to chart and

\footnotetext{
${ }^{5}$ The same could be said about residence permits (hukou). Despite diminishing importance, hukou remains a prerequisite for employment and mobility of Chinese people.
} 
steer its political trajectory. In fact, the higher the administrative rank of a society's leadership, the more important the society is, the higher the possibility of access to resources, and as a result the less autonomous it becomes. This explains why the CAST, an umbrella organization of Chinese academic societies as well as various associations of science and technology (kexie), equivalent to some extent to the AAAS, ${ }^{6}$ has been led by a vice chairman of the National People's Congress Standing Committee, China's highest state organ and legislature. Moreover, despite its claimed grassroots, academic, public-goods, non-profit, and non-government characteristics, the entire kexie system from the CAST at the central level down to a district also represents another channel through which the CCP exerts its leadership over China's scientific enterprise (CAST 2005). It is no surprise that there is a party apparatus throughout, no different from any other Chinese organization. In fact, the day-today operation is run by the party secretary who is likely to be a member of the CCP Central Committee, while the CAST as a whole is under the direct leadership of the Secretariat of the CCP Central Committee with a Politburo member in charge. All these determine the interdependence between the academic society and the state and especially the party, which controls the kexie system and indeed entire scientific enterprise.

That said, this does not mean that China's academic societies have no room to maneuver. The CAST has tried to be visible and relevant in Chinese science, at least on the academic side. It has proposed and indeed convened its annual conference since 1999 at various Chinese cities on various themes, following the model of the AAAS annual conference. China's academic societies also have tried to advocate for self governance and maintenance of integrity in research. For example, at the turn of the century, in response to a debate whether nuclei acid functions as a nutrition, the Chinese Society of Biochemistry and Molecular Biology stipulated that its members should neither publish articles in newspapers nor give opinions that could be used as advertisement nor participate in business activities in the name of the society as some of its members had done (Tsou 2001). In recent years, the CAST has been actively voicing the concerns of its constituents based on surveys and internal studies and informing China's scientific and political leadership of the challenges in science and innovation. However, the CAST and its affiliated societies could only "fly within a birdcage" or act according to the rules set by their political patron. They are unable to take an independent stand in, say, fighting against misconduct in science, as discussed, even if the

\footnotetext{
${ }^{6}$ While the CAST is an umbrella organization of China's academic societies, U.S.-based academic societies are not affiliated with the AAAS.
} 
issue is well within their mission of serving as the vanguard of scientific values and norms. The CAST, for example, must acquire the approval of the Secretariat of the CCP Central Committee to start its annual conference.

Our examination of the above cross-cutting issues seems to indicate that in China, whereas science is in "excess" in many dimensions that is materialistic and methodological, an adequate understanding of science from the perspectives of institution, culture and values is still "deficient" (MacPhail 2009). ${ }^{7}$ The rationale of focusing on scientific methodology and favoring scientific discoveries, or the tangibles, has been reinforced at the expense of cultural aspects of science, or the intangibles. Under these circumstances, many of the best practice either has not been introduced or has been exercised distortedly; good governance has not been implemented to ensure the smooth proceed of high-quality research.

\section{Conclusion and Discussion}

A slew of measures - from increasing human resources to the rise of Chinese scientific publications and others - indicate that China's scientific and especially technological capabilities are as high as they ever have been and still are rising. But they do not suggest that the morale of Chinese scientists also has hit an all-time high. In spite of or because of the new development at the front of science and innovation, there have been circumstances that have led to various pathetic problems in Chinese science. For example, the way in which the increasing financial resources are distributed is not meritocratic; scientists are not encouraged to be skeptical toward existing theories, especially those by senior scientists who control resources; discrimination is widespread as the institution where a scientist receives his or her education and works determines the outcome of appointment, promotion, funding, reward, and others. There is a cynicism among scientists who do not trust the system and believe and complain that they are being unfairly treated. China's cultural environment also does not tolerate failure in research, although the revised Law of Progress in Science and Technology stipulates changes (Qiu 2007). Consequently, Chinese scientists are more likely preoccupied with research that could yield quick and often achievable outcomes as they know known risks if they fail to explore the unknown. Research is too often derivative in nature which has become a form of "soft corruption," not only wasting resources but also discouraging creativity. And a series of high-profile scientific scandals

\footnotetext{
${ }^{7}$ While many of the problems described here are commonplace in all systems, it is a matter of degree.
} 
involving some leading scientists at China's top universities and research institutes have raised public concerns over and international attention to the supervision and governance of research activities. Indeed, how the big economic and political dilemmas facing Chinese science are solved is inextricably bound up with social questions of trust, governance, and values.

With a more pragmatic approach, China values science, but does not necessarily accept the values of science, which could be detrimental for its ambitions, including being awarded the Nobel Prize in science and becoming a real scientific power. Underlining the prize and indeed modern science is not merely methodology and materialism but culture, which, in Merton's systematic perspective of science, discussed at the outset, is higher on the value proposition of science. Although the values themselves have changed over time, the core that remains includes truth-seeking, intellectual curiosity, challenging authority, and above all, freedom of inquiry. And such practices as reward system, integrity in research, and autonomy of the scientific community reflect and enforce these values, whose universal observation has to be sustained across the system of science and followed by scientists all over the world. It is in this sense that there is no such thing as the "Chinese" science, "American" science or "French" science, or the science with "Chinese," "American," or "French" characteristics. ${ }^{8}$

Indeed, while long tradition in theoretical subjects and mathematics that fits the Nobel system, the extraordinary cultural value and importance that the former Soviet Union attached to science and knowledge may explain the continuous production of the Nobel Prizes in the seemingly totalitarian regime (Kojevnikov 2004). Recent historiography of Soviet science characterizes the relations between scientists and politicians as interaction and dialogue rather than control and dependence, except between 1928 and 1932 when the purge targeting the political elite brought collateral damage to the intelligentsia. Lysenko's influence seems to be confined to agricultural science. Moreover, respect for professionals and knowledge, a pre-revolution Russia tradition, not only survived but also was reinforced in the Soviet era. Leading non-party-member scientists occupied top positions at academic institutions, some of which were created solely for them, and they enjoyed a privileged social status and a lifestyle that was "bourgeois" even by today's standard. Maintenance of considerable degree of autonomy at institutions of learning was tolerated. Consequently,

\footnotetext{
${ }^{8}$ New phenomena that emerge in a dramatically changing China are often labelled as having "Chinese characteristics" (Huang 2008).
} 
Soviet's materialistically poor support for research did not prevent its scientists from managing to achieve impactful breakthroughs, reflected in a series of Nobel Prizes, which in turn pleased the political leadership, including Stalin, to reward the scientific community and tolerate the criticism brought by elite scientists such as Ivan Pavlov, Lev Landau, and Piotr Kapitza on communist policies. While the Soviet case may lend some support to the alternative model of doing "good" science, the emphasis here is the fact that some of the norms of science were preserved. And given their wisdom and tradition in knowledge production, Soviet scientists could have definitely done better in a more liberal environment. Unfortunately, China's scientific and political leadership did not learn this lesson from the Soviet experience.

In his editorial for Science, the leading international science magazine, Ismail Serageldin, director of Egypt's Library of Alexandria, laments:

As the British scientist Jacob Bronowski observed more than half a century ago, the enterprise of science requires the adoption of certain values that are adhered to by its practitioners with exceptional rigor. These values also provide the basis for enhancing human capabilities and human welfare. Truth and honor are of the utmost importance. Any scientist who manufactures data risks being ostracized indefinitely from the scientific community, and he or she jeopardizes the credibility of science for the larger society. A scientist may err in interpreting data, but no one can accept the fabrication of data. ... Science requires the freedom to enquire, to challenge, to think, to imagine the unimagined. It cannot function within the arbitrary limits of convention, nor can it flourish if it is forced to shy away from challenging the accepted. (Serageldin 2011)

The editorial, written amid the Arab Spring of 2011, called for embracing the values of science in the building of a new Arab society. His statement seems applicable to China as well.

In 2005, Qian Xuesen, father of China's missile and space program, told visiting Chinese Premier Wen Jiabao that one important reason that China has not turned out outstanding talent is that the nation does not have even one university that genuinely follows the model of nurturing scientific and creative talent and encourages unique innovation. Qian did not elaborate what he meant with his question, thus leaving room for interpretation and debate. However, given his thorough understanding of China's education and research system 
from his vantage point as well as his formative personal and professional life experience in the U.S. - he had studied and worked at the Massachusetts Institute of Technology and the California Institute of Technology for 20 years before being expelled in the mid-1950s amid the McCarthyism zeal (Chang 1995) - he was likely to imply the importance of such values as independent thinking, tolerance of dissent, and freedom of inquiry.

Five years later, in 2010, in soliciting comments from university presidents and professors on his report to the coming session of the National People's Congress, then Premier Wen Jiabao indicated that "a good university must have its own unique soul, which is independent thinking and freedom of expression" (Zhao 2010). Premier Wen seemed to echo and perhaps gave an explicit answer to the "Qian Xuesen question," although he did not explicate that he was doing so. Coincidentally, around the same time, Richard Levin, the president of Yale University, predicted that China's top universities possibly surpass Oxford, Cambridge and the Ivy League universities. While using the expanded capacity of China's higher education system, a large talent pool, and an increasing number of returnees to support his prediction, President Levin also pointed out the deficits of Chinese universities in the cultivation of critical thinking and the allocation of abundant resources based on guanxi, seniority or political influence (Shepherd 2010).

Upon close examination, greatness for universities and science is not achieved simply through possessing sophisticated facility, high-quality students and faculty, and plentiful resources, all of which are relatively easy to attain. The difficult and important part is to nurture independent thinking and freedom of inquiry, while its absence in China as well as in the former Soviet Union, according to Jonathan R. Cole, the former provost of Columbia University, "has limited the pool of academic talent and stultified imagination and innovation," through his study of the American university (2010: 114). Therefore, to make its universities "world-class," the Chinese state should allow them have a "soul," which is not only unique but also universal, by valuing free inquiry and academic freedom and treasuring and upholding universal values of science. China must not be preoccupied with the Nobel Prize from a materialistic perspective and must not practice science without an appropriate appreciation of the ultimate values embodied in it. Otherwise, its universities may surpass Oxford, Cambridge, Yale or Columbia measured by various tangible indicators but never reach the intangible status of these truly world-class institutions as President Levin predicted; its scientists may stand a chance of winning the Nobel Prize but never leapfrog to the international frontiers of research that has been envisioned. 


\section{Acknowledgements}

The author would like to thank Jonathan R. Cole, Christopher Howe, Li Liu, Richard P. Suttmeier and two anonymous reviewers for their critical and constructive comments on early versions of the paper. The author has also benefited from comments made by participants of a seminar at the University of Nottingham. Partial support for this work came from a U.S. National Science Foundation grant (SES-0925015).

\section{References}

Anderson, Melissa S., Emily A. Ronning, Raymong De Vries, and Brian C. Martinson. 2010. Extending the Mertonian norms: Scientists' subscription to norms of research. The Journal of Higher Education 81 (3): 366-393.

Barboza, David. 2006. In a scientist's fall, China feels robbed of glory. The New York Times May 15: 1 .

Baum, Richard. 1982. Science and culture in contemporary China: The roots of retarded modernization. Asian Survey 22 (12): 1166-1186.

Ben-David, Joseph. 1984. The Scientist's role in society: A comparative study. Chicago, IL: University of Chicago Press, 2nd edition.

Bi, Jian. 2009. Why the first-class awardees of the National Science and Technology Progress Award all administrators? Dongfang Daily 15 January: A23.

Bourdieu, Pierre. 1975. The specificity of the scientific field and the social conditions of the progress of reason. Social Science Information 14: 19-47.

China Association for Science and Technology (CAST). 2005. Thoughts on the position of the associations for science and technology in the early 21 st century (in Chinese). Available online at http://www.cast.org.cn/n35081/n35668/n35728/n36434/n36509/10194219.html (assessed 18 December 2012).

China Association for Science and Technology (CAST). 2009. Chinese science and technology professionals believe misconduct in science a protruding problem in China today. Available online at http://english.cast.org.cn/n1181872/n1182018/n1182077/11368185.html (accessed 18 December 2012).

Cao, Cong. 2004a. China's scientific elite. London and New York: RoutledgeCurzon.

Cao, Cong. 2004b. China’s "Nobel Prize complex." Minerva 42: 151-172.

Chang, Iris. 1995. Thread of the silkworm. New York: BasicBooks. 
Cole, Jonathan R. 2010. The great American university: Its rise to preeminence, its indispensable national role, why it must be protected. New York: Public Affairs.

Collins, Harry M. 1982. Knowledge, norms and rules in the sociology of science. Social Studies of Science 12: 299-309.

Cyranoski, David. 2004. Biologists lobby China government for funding reform. Nature 430 (26 July): 495.

Cyranoski, David. 2012. Research ethics: Zero tolerance. Nature 481 (12 January): 134-136.

Gibbons, Michael, Camille Limoges, Helga Nowotny, Simon Schwartzman, Peter Scott, and Martin Trow. 1994. The new production of knowledge: The dynamics of science and research in contemporary societies. London: Sage.

Hu, Danian. 2005. China and Albert Einstein: The reception of the physicist and his theory in China, 1917-1979. Cambridge, MA: Harvard University Press.

Huang, Yasheng. 2008. Capitalism with Chinese characteristics: Entrepreneurship and the state. Cambridge and New York: Cambridge University Press.

Holton, Gerald. 2004. Robert K. Merton (4 July 1910 - 23 February 2003). Proceeding of the American Philosophical Society 148 (4): 505-517.

IAP-IAC Committee on Research Integrity. 2012. Responsible conduct in the global research enterprise: A policy report. Alkmaar, The Netherlands: InterAcademy Council, IAP.

Jasanoff, Sheila. 2005. Designs on nature: Science and democracy in Europe and the United States. Princeton, NJ: Princeton University Press.

Kalleberg, Ragnvald. 2007a. Robert K. Merton: A modern sociological classic. Journal of Classical Sociology 7 (2): 131-136.

Kalleberg, Ragnvald. 2007b. A reconstruction of the ethos of science. Journal of Classical Sociology 7 (2): 137-160.

Kirby, William C. 1989. Technocratic organization and technological development in China, 1928-1953. In Science and technology in post-Mao China, eds. Denis Fred Simon and Merle Goldman, 23-44. Cambridge, MA: Harvard University Press.

Kojevnikov, Alexei B. 2004. Stalin's great science: The times and adventures of Soviet physicists. London: Imperial College Press.

Lancet. 2010. Scientific fraud: Action needed in China. Lancet 375 (9 January): 94.

Latour, Bruno and Steve Woolgar. 1986. Laboratory life: The construction of scientific facts. Princeton, NJ: Princeton University Press. 
Li, Xiguang and Xiong Lei. 1996. Scientific misconduct: Chinese researchers debate rash of plagiarism cases. Science 274 (18 October): 337-338.

Li, Zhenzhen. 1995. 1956: Positioning China's science system under the planning economic system (in Chinese). Journal of the dialectics of nature 17 (6): 35-45.

Liu, Hong and $\mathrm{Hu}$ Xinhe. 2011. An empirical study of retraction of published papers in international journals: The case of ScienceDirect database (in Chinese). Chinese journal of scientific and technical periodicals 22 (6): 849-852.

Liu, Zhiqing. 2007. Academician co-authored papers are confirmed plagiarized (in Chinese). Jinghua times 13 July: 7.

Lovell, Julia. 2006. The politics of cultural capital: China's quest for a Nobel Prize in Literature. Honolulu, HI: University of Hawaii Press.

MacPhail, Theresa. 2009. The "problem" of science in China. East Asian science, technology and society: An international journal 3: 27-50.

Mendelsohn, Everett. 1989. Robert K. Merton: The celebration and defense of science. Science in context 3 (1): 269-289.

Merton, Robert K. 1973 [1942]. The normative structure of science. In The sociology of science: Theoretical and empirical investigations, ed. Norman W. Store, 267-278. Chicago, IL: University of Chicago Press.

Merton, Robert K. 1973 [1957]. Priorities in scientific discovery. In The sociology of science: Theoretical and empirical investigations, ed. Norman W. Store, 286-324. Chicago, IL: University of Chicago Press.

Miller, H. Lyman. 1996. Science and dissent in post-Mao China: The politics of knowledge. Seattle, WA: University of Washington Press.

Mitroff, Ian I. 1974. Norms and counter-norms in a select group of the Apollo moon scientists: A case study of the ambivalence of scientists. American sociological review 39: 579-595.

Mulkay, Michael J. 1969. Some aspects of cultural growth in the natural sciences. Social research 36: 22-52.

Mulkay, Michael J. 1976. Norms and ideology in science. Social science information 15: 637-656.

Nature. 2005. Diversionary tactics. Nature 436 (14 July): 152.

Needham, Joseph. Various years. Science and civilisation in China. Cambridge: Cambridge University Press. 
Panofsky, Aaron L. 2010. A critical reconsideration of the ethos and autonomy of science. In Robert K. Merton: Sociology of science and sociological explanation, ed. Craig Calhoun, 140-163. New York: Columbia University Press.

Pei, Minxin. 2006. China's trapped transition: The limits of developmental autocracy. Cambridge, MA: Harvard University Press.

Peng, Bin. 2009. Member of the Chinese Academy of Engineering Liu Xingtu apologized to Professor Li Jiandong by bowing (in Chinese). China youth news 4 March: 7.

Poo, Mu-ming. 2004. Big science, small science (in Chinese). Nature 432, China voice II (18 November): A18-A23.

Qiu, Jane. 2007. Chinese law aims to quell fear of failure. Nature 449 (6 September): 12. Qiu, Jane. 2010. Publish or perish in China. Nature 463 (12 January): 142-143.

Rao, Yi, Bai Lu, and Chen-Lu Tsou. 2004. Fundamental transition from rule-by-man to ruleby-merit: What will be the legacy of the Medium to Long-Term Plan of Science and Technology?" (in Chinese). Nature 432, China voices II (18 November): A12-A17.

Schneider, Lawrence. 2003. Biology and revolution in the Twentieth-Century China. Lanham, MD: Rowman \& Littlefield Publishers.

Shen, Xiaobai and Robin Williams. 2005. A critique of China's utilitarian view of science and technology. Science, technology \& society 10: 197-224.

Serageldin, Ismail. 2011. The values of science. Science 332 (3 June): 1127.

Shepherd, Jessica. 2010. China's top universities will rival Oxbridge, says Yale president. The Guardian: 2 February 2012. Available online at http://www.guardian.co.uk/education/2010/feb/02/chinese-universities-will-rivaloxbridge (accessed 18 December 2012).

Shorett, Peter, Paul Rabinow, and Paul R. Billings. 2003. The changing norms of the life sciences. Nature Biotechnology 21:123-125.

Suttmeier, Richard P. 1985. Corruption in science: The Chinese case. Science, technology, \& human values 10: 49-61.

Suttmeier, Richard P. 1987. Riding the tiger: The political life of China's scientists. In Citizens and groups in contemporary China, ed. Victor C. Falkenheim, 123-158. Ann Arbor, MI: Center for Chinese Studies, the University of Michigan.

Suttmeier, Richard P. 2011. In search of "the Chinese way of science": Policy debates and the challenge of harmonizing discordant voices. Paper presented at the Conference on “The political economy of China's technology and innovation policies." La Jolla, CA: University of California Institute of Global Conflict and Cooperation, 27-28 June. 
Tsou, Chen-Lu. 2001. Scientists should not be "advertising stars" (in Chinese). Wenhui bao October 10.

Turner, Stephen. 2007. Merton's “norms” in political and intellectual context. Journal of classical sociology 7 (2): 161-178.

Wang, Hui. 2011. The concept of "science" in modern Chinese thought. Journal of modern Chinese history 5: 45-67.

Wang, Shuntong, Qiyi Shen, and Zhenning Gao (comps.). 1994. The China Association for Science and Technology (in Chinese). Beijing: Contemporary China Press.

Wang, Zuoyue. 2002. Saving China through science: The Science Society of China, scientific nationalism, and civil society in Republican China. Osiris: A research journal devoted to the history of science and its cultural influences 17: 291-322.

Wei, Nancy Chunjuan and Darryl E. Brock. 2012. Mr. Science and Chairman Mao's Cultural Revolution. Lanham, MA: Lexington Books.

Williams, James H. 1990. Fang Lizhi's big bang: A physicist and the state in China. Historical studies in the physical and biological sciences 30: 50-87.

Ye, Tieqiao. 2009. The award to Sanlu Group reflects the problems of the National Science and Technology Progress Award (in Chinese). China youth news 10 March: T4.

Ye, Tieqiao and Yu Lei. 2011. The Ministry of Science and Technology revoked a National Science and Technology Progress Award for misconduct (in Chinese). China youth news February 11: 1.

Yearley, Steven. 2005. Making sense of science: Understanding the social study of science. London: SAGE Publications, 2005.

Zeng, Weiqin and David Resnik. 2010. Research integrity in China: Problems and prospects. Developing world bioethics 10: 164-171.

Zhang, Yuehong. 2010. Chinese journal finds 31\% of submissions plagiarized. Nature 467 (9 September): 153.

Zhao, Cheng. 2010. Wen Jiabao: University must have a soul of independent thinking and freedom of expression (in Chinese). People's daily February 2: 2.

Ziman, John. 1990. Research as a career. In The Research System in Transition, eds. Susan E. Cozzens, Peter Healey, Arie Rip, and John Ziman, 345-359. Dordrecht: Kluwer.

Ziman, John. 2000. Real science: What it is and what it means. Cambridge: Cambridge University Press.

Zuckerman, Harriet. 1988. The sociology of science. In Handbook of Sociology, ed. Neil J. Smelser, 511-574. Newbury Park, CA: Sage. 